\title{
Radar-Rainfall Estimation from S-band Radar and its Impact on the Runoff Simulation of a Heavy Rainfall Event in the Huaihe River Basin
}

\author{
Yufang GAO \\ Jiangsu Provincial Key Laboratory of Agricultural Meteorology, College of Applied Meteorology, \\ Nanjing University of Information Science and Technology, Nanjing, China \\ Yaodeng CHEN \\ Collaborative Innovation Center on Forecast and Evaluation of Meteorological Disasters, NUIST, Nanjing, China
}

Lina ZHANG

China Meteorological Administration Training Center, Beijing, China

and

Tao PENG

Hubei Key Laboratory for Heavy Rain Monitoring and Warning Research, Institute of Heavy Rain, CMA, Wuhan, China

(Manuscript received 21 April 2015, in final form 29 October 2015)

\begin{abstract}
From July 1 to 13, 2007, a widespread heavy rainfall event occurred in the Huaihe River Basin (HB) in China, with an average rainfall of nearly $465 \mathrm{~mm}$ in the area. The main purpose of this study is to integrate a rainfall estimate by the China New Generation Weather Radar S-band radar (CINRAD-SB) into the Hydrologic Engineering Center's Hydrologic Modeling System (HEC-HMS) and analyze the CINRAD-SB rainfall estimation and its impact on the runoff simulation of this type of rare flood event in a region with complex terrain.

For the CINRAD-SB rainfall estimation four methods are considered: (1) $\mathrm{Z}=300 \mathrm{R}^{1.4}$ (Z: radar reflectivity, $\mathrm{R}$ : rainfall intensity); (2) a rainfall estimation error adjustment by using a Kalman Filter (KF); (3) Optimal Interpolation (OI); and (4) the Union method, which is composed of KF and OI. The HEC-HMS is used to investigate the spatial and temporal distribution of the CINRAD-SB rainfall and its impact on the hydrological simulation of the event.

Rainfall estimations from the four methods are compared with rain gauge observations. The four methods underestimate the precipitation amounts, while for the Union method the values of the relative bias are closer to zero. The relative bias values of the four methods vary with different rainfall intensity, those of the Union method vary the least among the four methods. This evaluation indicates that runoff simulations based on radar-rainfall could
\end{abstract}

Corresponding author: Yufang Gao, College of Applied Meteorology, Nanjing University of Information Science \& Technology, 219 Ning Liu Street, Nanjing 210044, P. R. China

E-mail: gaoyf@nuist.edu.cn

(C)2016, Meteorological Society of Japan 
reproduce similar overall patterns to the observed streamflow. The peak discharge contains obvious improvements - for instance, the skill score is 0.6 - in model runs with forcing that is provided by the Union method vs. rain gauge data. These results might guide the improvement of hydrological predictions that are driven by radar rainfall.

Keywords radar; gauge; rainfall-runoff; HEC-HMS

\section{Introduction}

The Huaihe River Basin (HB) is located in the eastern region of China between the Yangtze River and Yellow River in an area that is described by east longitude $111^{\circ} 55^{\prime}$ to $121^{\circ} 25^{\prime}$ and north latitude $30^{\circ} 55^{\prime}$ to $36^{\circ} 36^{\prime}$ (see Fig. 1). The watershed area is approximately $2.7 \times 10^{5} \mathrm{~km}^{2}$ and is composed of the Huaihe River, Yihe River, Shuhe River, and Sihe River. The $\mathrm{HB}$ is located in the north-south climate transition zone, and the area's climate matches a semi-humid monsoon environment. The cumulative mean rainfall is $880 \mathrm{~mm}$ per year, and the rainfall from June to September predictably accounts for $70-80 \%$ of the annual rainfall (Chen et al. 2014). The HB is surrounded on three sides by mountains and faces the sea to the east. Mountains and hills account for approximately one-third of the total area. The upper and middle reaches of the Huaihe River are composed of a large number of tributaries, which originate from mountainous and hilly areas. Rapid streams converge soon after a rainstorm occurs, resulting in enormous pressure on the main stream of the Huaihe River. In addition, the cross section of the Huaihe main river is narrow, and the slope of the middle reaches is notably small (the total length is $1000 \mathrm{~km}$ and the river drop is $200 \mathrm{~m}$ ). The $\mathrm{HB}$ is characterized by significant features of rainstorm outbreaks and the frequent occurrence of flood disasters. The HB is one of the areas in China that is highly vulnerable to flooding. Since the 1950s, major floods have occurred in the HB, including events in 1954, 1991, 2003, 2005 and 2007 (Zhao et al. 2007). The climate produces frequent heavy rains in the summer months, and the unique geography that forms the HB, which has multiple branches and flat riverbeds, makes the HB a unique region with significant challenges for developing flooding alert/warning systems.

The new-generation weather radar network (CINRAD) is an observation network that is composed of 158 Doppler weather radar systems in China (Chu et al. 2013). Approaches that make full use of the huge amount of radar data in hydrome- teorological forecasting have become a key issue. Weather radar detects the motion of rain droplets in addition to the intensity of the precipitation at a high spatial resolution over continuous regions and is also of interest for measuring rainfall in ungauged basins. These data can provide continuous rainfall estimates over a large area, which makes this system ideal to evaluate radar-based precipitation estimates for use in flood modeling applications for a variety of storms, basins, and distributed hydrologic models.

Because of its complex water system and steep terrain, the HB historically has been one of the most difficult areas to forecast flooding both in theory and in practice. The coupling of radar-rainfall estimates with hydrological models is expected to improve runoff prediction (Su et al. 2008).

The objective of this study is to integrate radar-rainfall estimates into a hydrological model of the HB. A heavy rainfall event that occurred in the HB during the summer of 2007 is chosen to investigate how well the weather radar can reproduce the hydrographs and hydrologic responses based on the radar rainfall estimation errors.

Six S-band new-generation weather radar systems (the China New Generation Weather Radar S-band Radar; CINRAD-SB) and more than 2000 rain gauges are available over the HB. Currently, the $\mathrm{Z}$ (radar reflectivity)-R (rainfall intensity) relationship $\left(\mathrm{Z}=300 \mathrm{R}^{1.4}\right)$ is used to estimate precipitation for the CINRAD-SB. However, a single Z-R relationship is inadequate to account for the deviation between the radar rainfall and actual rainfall because of various factors, i.e., the season, the region and the nature of the precipitation. Error sources in radar-rainfall estimation have been investigated in previous studies (e.g., Wilson and Brandes 1979; Austin 1987; Kitchen and Jackson 1993; Joss and Lee 1995), including radar systematic error, range-dependent systematic error and random error. Studies have been conducted to correct errors from different sources in radar rainfall estimation (Dinku et al. 2002). Habib et al. (2008) noted that bias adjustment is an important approach to obtain high-quality radar rainfall estimates, but 


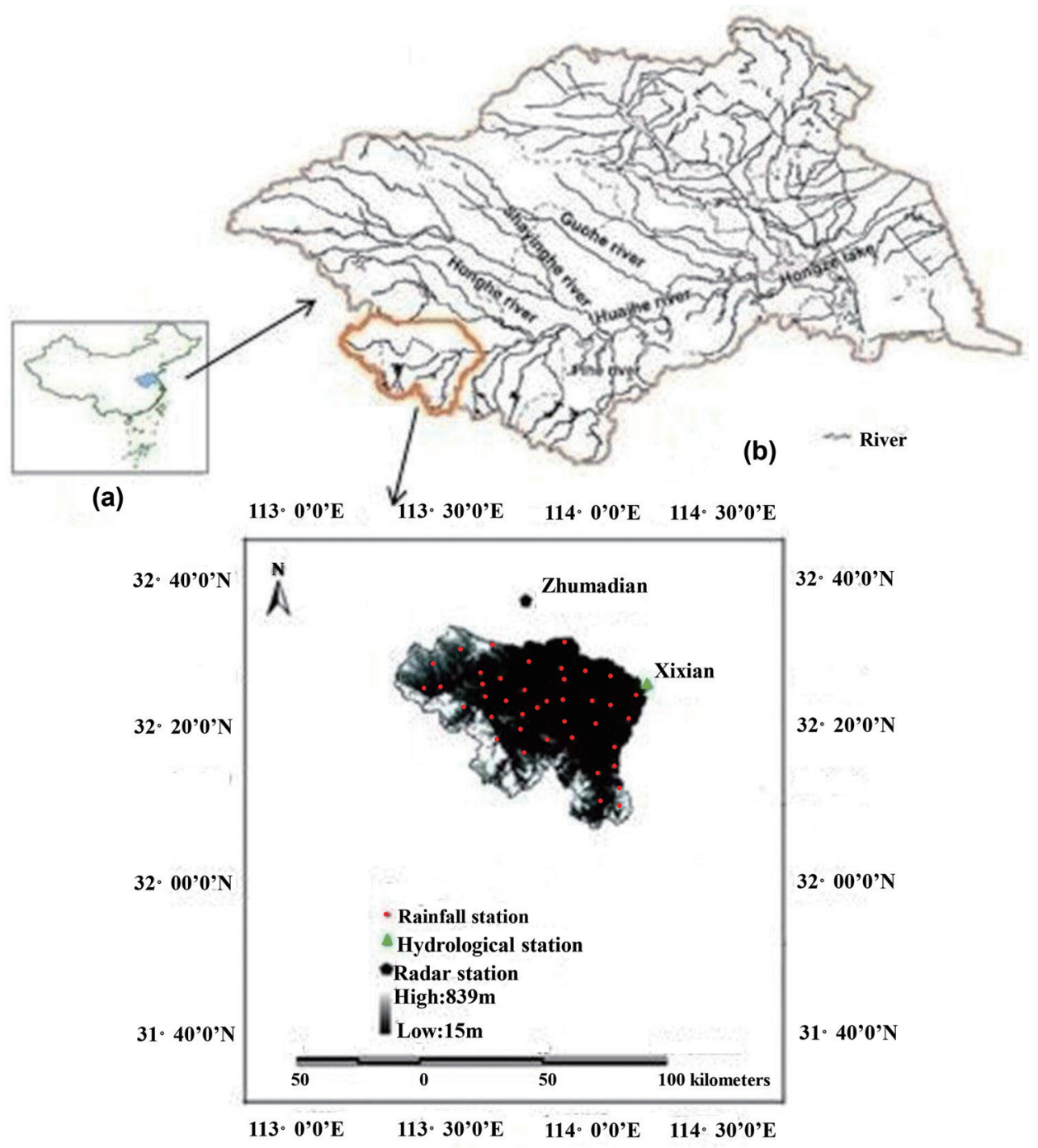

(c)

Fig. 1. Study domain: (a) Map of China, (b) Huaihe River Basin and location of the Xixian watershed, (c) Digital elevation model of the Xixian watershed. Rain gauge stations and hydrological stations are shown as symbols, which are indicated in the legend.

even the most careful calibration and validation for radar rainfall estimates cannot completely eliminate the problems that are introduced by the reflectivity measurement process. Because radar rainfall drives the hydrological model, the quantification of the hydrologic quality of rainfall estimates from radar will aid in understanding the runoff error and optimizing the runoff predictions from using radar rainfall estimates.

Studies of rainfall estimates have been performed by using radar data as input to hydrologic models.
Moon et al. (2004) evaluated Next Generation Weather Radar (NEXRAD) daily rainfall data on a $4 \times 4-\mathrm{km}$ grid scale by using gauge data in a 2608 $\mathrm{km}^{2}$ watershed in east-central Texas in the US. The authors found that the radar underestimated the rainfall by approximately $80 \mathrm{~mm}$ on average over a 16-month period (1999-2001). Sharif et al. (2004) used the Cascade Two-Dimensional model (CASC2D) to understand the impact of radar rainfall estimation errors on runoff predictions with an emphasis on the distance from the radar to the catchment in a small 
infiltration-excess watershed. Sensitivity analysis indicated that the variance of the hydrograph prediction error from the radar rainfall error decreases as the event magnitude increases. Habib et al. (2008) studied a watershed with a fairly steep topography and a drainage area of $21.4 \mathrm{~km}^{2}$ to analyze radar-rainfall estimation errors and their propagation throughout the hydrological models. The analysis results indicated that the adjustment of radar biases resulted in significant improvements in the runoff predictions. Gourley et al. (2010) studied the impact of radar estimation errors on hydrologic simulation. The results indicated that only after long-term biases were corrected did all the polarimetric rainfall estimators outperform the conventional algorithm. In China, a wide range of studies have focused on streamflow simulations by using radar and gauge rainfall data sets. Liu and $\mathrm{Li}$. (2004) and Li et al. (2004) found that combining radar rainfall with rain gauge observations improved hydrologic simulations compared to studies that used only rain gauge data.

The Hydrologic Engineering Center's Hydrologic Modeling System (HEC-HMS) is a rainfall-runoff model that has been widely used in humid, semihumid and semi-arid regions for flood forecasting. Knebl and Yang (2008) developed a framework for regional-scale flood modeling that integrated NEXRAD rainfall and the HEC-HMS model. Investigations of the modeling demonstrated the feasibility of using real-time products from gridded rainfall to drive the HEC-HMS model. Eloise and Atkinson (2011) selected the HEC-HMS model to assess the accuracy of precipitation in a simulation of river flows for an extreme event. Gauge, radar and gauge-corrected radar rainfall data were used as the HEC-HMS model inputs. Song et al. (2011) applied the HEC-HMS model of the Louzigou Basin to a tributary basin of the $\mathrm{HB}$, and the results showed that the HEC-HMS model produced highly accurate simulations.

Although studies on the use of radar rainfall as input data for hydrological models have been performed previously (Li et al. 2004; Xu et al. 2007; Yang et al. 2009; Niu et al. 2014), few studies have focused on the HB, a region with complex topography in which inaccurate radar scans and gauge density are important factors that affect the accuracy of results. In this study, the performance of four rainfall estimates from CINRAD-SB data is examined to determine their impacts on hydrological simulations.

We integrate the CINRAD-SB-derived rainfall into the HEC-HMS model to illustrate how the radar-rain- fall estimation errors influence the hydrological prediction skills via the HEC-HMS model in the Xixian watershed (see Fig. 1), which is located at the headwater of the HB. Section 2 describes the study domain of the Xixian watershed and the details of the rainfall-runoff event. Section 3 presents the radar rainfall analysis by comparing the CINRAD-SB rainfall with that of the rain gauges. Section 4 describes the hydrologic model and the metrics that are used to assess the hydrologic performance with different rainfall inputs for the rare flood event. Section 5 presents a summary of the results, conclusions, and future topics of interest.

\section{Domain and rainfall-runoff event}

The Xixian watershed, which is located in the upper reaches of the Huaihe River, has a fairly steep topography with a drainage area of $10,190 \mathrm{~km}^{2}$ and is an important agricultural county that yields one billion kilograms of foodstuffs (Shi et al. 2003). The Xixian watershed is dominated by mountains and hills, and the terrain elevation in the watershed ranges from $15 \mathrm{~m}$ above mean sea level near the outlet to 839 $\mathrm{m}$. The catchment is located within the climatic transition zone between the northern subtropical and warm temperate regions. The mean annual precipitation was $946 \mathrm{~mm}$ for the years 1956-2008. The land use is primarily farmland, forestland and grassland, and the farmland area is always greater than $50 \%$. The soil type map is shown in Fig. 2 (Cai et al. 2012). A total of 71 precipitation gauges and 8 weather stations are located in this area, and the Xixian hydrologic station is situated near the outlet of the Xixian watershed. The cross-section width of the Xixian hydrologic station is $700-800 \mathrm{~m}$, the maximum flow measurement section width is $2470 \mathrm{~m}$ and the maximum water depth is $10.50 \mathrm{~m}$. Streamflow measurements from the Xixian hydrologic station are used in this study to evaluate hydrologic simulations that are forced by the CINRAD-SB rainfall estimates. The digital elevation model of the Xixian watershed with the rain gauge stations and the Xixian hydrological station is shown in Fig 1.

Heavy rainfall occurred during the period from June 19 to July 26, 2007, in the HB (Jiao et al. 2008; Zhao et al. 2007). Hereafter, this heavy rainfall event is called as the target event. The precipitation fell mostly from convective systems. The accumulated rainfall during the Meiyu period was the fourth heaviest in history since 1954 and was only less than that during the flood years of 1954, 1991 and 2003. In the Xixian watershed, heavy rainfall $\left(53-93 \mathrm{~mm} \mathrm{~d}^{-1}\right)$ 


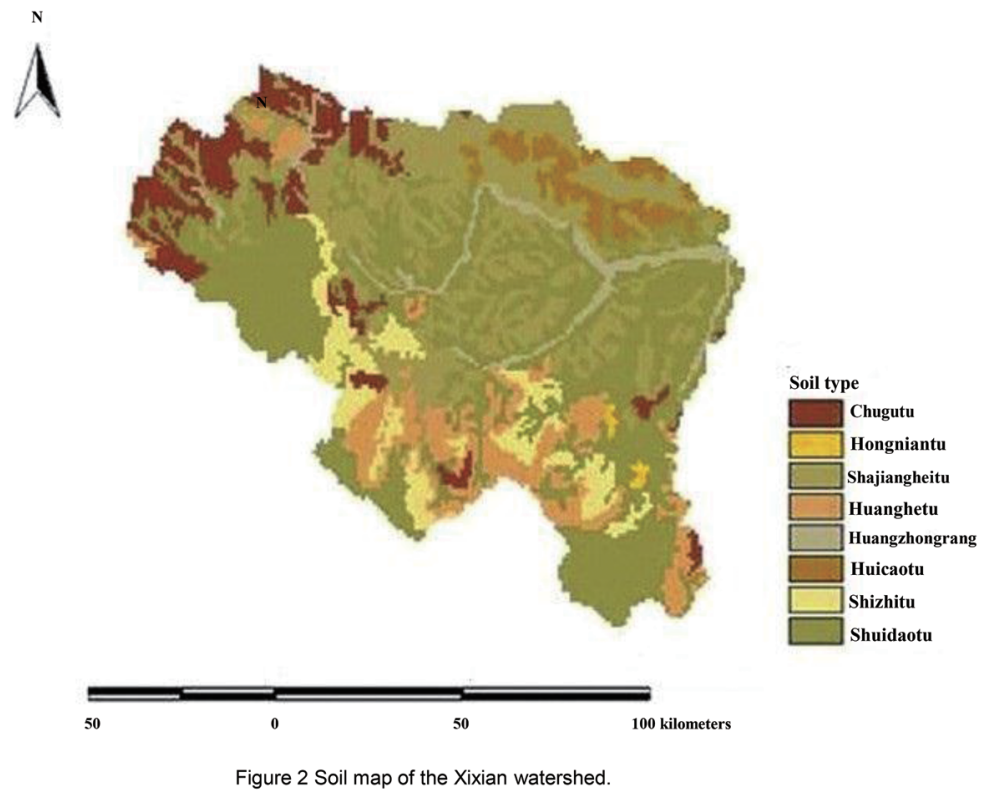

Fig. 2. Soil map of the Xixian watershed.

occurred primarily on July 1st, 3rd, 4th, 7th, 8th and 9th. On July 4th, 18 rain gauges reported rainfall of over $100 \mathrm{~mm} \mathrm{~d}^{-1}$, and 7 rain gauges reported rainfall of over $150 \mathrm{~mm} \mathrm{~d}^{-1}$. In this study, the precipitation period from July 1 to 13,2007 , was chosen to investigate rainfall-runoff with radar precipitation forcing.

\section{Radar rainfall estimation methodology and verification \\ 3.1 CINRAD-SB data and processing}

China has developed a new-generation Doppler weather radar (CINRAD) system based on the USA's Next-Generation Weather Surveillance Radar-1988 Doppler (WSR-88D) radar that can detect rainfall within a radius of $230 \mathrm{~km}$. The CINRAD-SB radars operate in the S-band, and their characteristics are similar to those of the WSR-88D radars in the US operational Doppler radar network. The radar volume scan consists of 9 elevation angles $\left(0.5^{\circ}, 1.5^{\circ}, 2.4^{\circ}\right.$, $3.4^{\circ}, 4.3^{\circ}, 6.0^{\circ}, 9.9^{\circ}, 14.6^{\circ}$ and $19.5^{\circ}$ ) over $6 \mathrm{~min}$ (Chu et al. 2013), and the CINRAD-SB rainfall data are retrieved at a spatial resolution of $1 \mathrm{~km}^{2}$. The watershed was located approximately $50-160 \mathrm{~km}$ from the CINRAD-SB radar site in Zhumadian at $32.98^{\circ} \mathrm{N}, 116.02^{\circ} \mathrm{E}$ (marked as Zhumadian in Fig. 1), and the radar's scanning radius is $230 \mathrm{~km}$. The reflectivity that was collected at a $0.5^{\circ}$ elevation angle was used to compute the rainfall rate (Huang et al. 2010). The quality of the raw radar echo is controlled, which is important for the accuracy of the derived rain products, and a brief summary of the quality control procedure is provided by Huang et al. (2010). Precipitation rates that are computed from each algorithm are aggregated into hourly accumulation data and processed into a format that is compatible with the HEC-HMS model.

\subsection{Description of the radar rainfall methods}

The recent radar network provides continuous timespace rainfall estimates, but the estimation methodology has limitations. Therefore, gauge rainfall is commonly used to correct the radar rainfall estimation.

During the radar coverage periods, 40 independent automated tipping-bucket gauges (Fig. 1) supplied data in near-real time. These rain gauges are used to compare, correct and verify radar rainfall and to drive the HEC-HMS model.

The one-hour rainfall datasets from 7/1/2007 00:00 to $7 / 13 / 200720: 00$ were used to obtain quantitative precipitation estimates over the entire watershed, including (1) $\mathrm{Z}=300 \mathrm{R}^{1.4}$; (2) a rainfall estimation calibration based on a Kalman Filtering approach that was proposed by Chumchean et al. (2004); (3) Optimum Interpolation (Nehrkorn and Hoffman 1996); and (4) the Union method, which integrates the Kalman Filter with the Optimal Interpolation (Huang et al. 2010). Hereafter these four methods are referred 
to as the Z-R, KF, OI and Union methods, respectively.

Kalman filtering techniques are used to correct the mean field bias in real time to eliminate the interference of random noise on radar precipitation estimation. The Kalman filter mathematical model includes two components, namely, the process equation and the measurement equation (Yin and Zhang 2005).

First, we define the deviation calibration factor $B_{k}$ :

$$
B_{k}=\frac{G_{k}}{R_{k}},
$$

where $G_{k}$ is the rainfall intensity for rain gauges at time step $k$ over the radar coverage area and $R_{k}$ is the rainfall intensity for the radar at the same time. If the rainfall data from the radar and rain gauge are accurate, the process deviation $B_{k}$ will be 1 . However, in actual measurements, $B_{k}$ is not equal to 1 because of many interference factors and is updated with time $k$. The change in $B_{k}$ is random. We assume that the deviation $B_{k}$ follows a random process that is governed by the stochastic equation:

$$
B_{k+1}=B_{k}+\omega_{k},
$$

with a measurement deviation $Z_{k}$ :

$$
Z_{k}=B_{k}+v_{k},
$$

where $\left\{\omega_{k}\right\}$ represents the process noise with zero mean, $\left\{v_{k}\right\}$ denotes the measurement noise with zero mean, $\left\{\omega_{k}\right\}$ and $\left\{v_{k}\right\}$ are assumed to be independent of each other, $\left\{Z_{k}\right\}$ is a measurement deviation series, and $Z_{k}$ is given by

$$
\frac{\sum G_{i}(x, y)}{\sum R_{i}(x, y)\left(R_{i}(x, y)>0\right)},
$$

where $G_{i}(x, y)$ is the rainfall intensity for rain gauge $i$ which location is $(x, y), R_{i}(x, y)$ is the rainfall intensity from radar at the same place, and $R_{i}(x, y)>0$ is to ensure radar rainfall is nonzero.

Equations (2) and (3) constitute the Kalman filter mathematical model. Next, we establish a recursive equation and obtain the optimal $\left\{B_{k}\right\}$ with the minimum square error, and the calibrated radar rainfall $\widehat{R}_{k}$ is given by

$$
\widehat{R}_{k}=R_{k} B_{k / k-1},
$$

where $B_{k / k-1}$ is the deviation in the state at step $k$ based on the deviation in the state at step $k-1$.

The OI method follows the OI formulation
(Mikhail and Elvanden 1972). Values at each of the grid points are obtained from a linear combination of the Z-R rainfall, which represents the first background, and a weighted sum of the surrounding observation increments. The weights are determined by using a linear equation with coefficients that are given in terms of the observational and background error statistics. The corrected data for each grid are given by the following equation (Li and Zhang 1996):

$$
I_{k}^{a}=I_{k}^{g}+\sum_{i=1}^{N}\left(I_{i}^{o b}-I_{i}^{g}\right) P_{i},
$$

where $I_{k}^{a}$ is the corrected value from $I_{k}^{g}, k$ is the serial number for the grids, $I_{i}^{o b}$ is the observed value at the $i$ th rain gauge, $I_{i}^{g}$ is the radar-estimated rainfall value at the $i$ th rain gauge, $P_{i}$ is the weighting factor for the $i$ th rain gauge (if no radar data exist, the weighting factor is zero), $N$ is the number of rain gauges within a radius with $k$ as the center, and the radius is the minimum one that is needed to ensure that $N$ is equal to a specified constant.

The variances are assumed to be homogeneous and the co-variances to be both homogeneous and isotropic. Weighting factors can be obtained from the following equation:

$$
\sum_{i=1}^{N} P_{i} \mu_{i j}+\eta_{i} P_{j}=\mu_{k i} \quad(i=1,2, \ldots, N),
$$

where $\mu_{i j}$ is the autocorrelation coefficient between the values of rainfall at $i$ and $j$ and $\eta_{i}$ is the relative mean-square random observation error (in this study, $\eta_{i}$ approaches zero). According to Eq. (7), the weights depend on the scale of the function as represented by the autocorrelation coefficient $\mu_{i j}$. Equation (7) can be written as

$$
\sum_{i=1}^{N} P_{i} \mu_{i j}=\mu_{k i} \quad(i=1,2, \ldots, N),
$$

where $\mu_{i j}=\exp \left(-\frac{r_{i j}}{a}\right), r_{i j}$ is the distance between points $i$ and $j$, and a is the correlation radius. $\mu_{i j}$ decreases exponentially with increasing distance between points $i$ and $j$.

The following steps are performed to obtain these radar datasets:

1) The Point-Stat Tool in the Model Evaluation Tools (Development Tested Center 2010) is used to match the radar rainfall and rain gauge rainfall in the horizontal plane. The Model Evaluation Tools (MET), which were developed to evaluate the performance 
of numerical weather predictions, is used to evaluate forecasts or observations from other models or applications if certain file format definitions are followed (Development Tested Center 2010). The Point-Stat Tool matches the gridded data to the point observation locations by using several different interpolation approaches. We select the unweighted mean interpolation approach and define a width of 1 surrounding each observation point (see additional details in METv3.0 usage).

2) The 1-h gauge rainfall data that were matched with the radar data are divided into two groups. All the observed rain gauge rainfall data are arranged by latitude and longitude from top to bottom, left to right, and according to odd and even number sequence numbers; the gauges are divided into two groups, referred to as ob1 and ob2.

3) The ob1 rain gauge data are used to calibrate the radar precipitation estimations with the KF, OI and Union methods. The ob2 rain gauge data are used to validate the calibrated radar rainfall. The ob2 rain gauge data are subsequently applied to calibrate the radar precipitation estimations with the KF, OI and Union methods. The ob1 rain gauge data are used to validate the calibrated radar rainfall. During the rainfall process, the calibration work is performed for each hourly rainfall data set.

The Union method uses a procedure based on the assignment of a KF to eliminate the average deviation of the radar rainfall estimation in the time domain, and an OI is subsequently applied to perform spatial calibration. A KF and OI are used to revise any deviations from different causes; therefore, combining the Union method with these two methods is expected to improve the accuracy of the estimated regional precipitation.

\subsection{Rainfall comparison}

Advancements in weather radar and enhanced rainfall resolution have led to substantial improvements in real-time flood forecasting and the need to quantitatively characterize radar rainfall estimation errors. With the continual increase in the use of weather radar rainfall in hydrologic applications, traditional verification scores often provide poor information without attention to spatial information (Baldwin and Kain 2006; Casati and Wilson 2007). Numerous new methods that consider radar rainfall estimation error correlation in time and space have been proposed (e.g., Baldwin et al. 2002; Davis et al. 2006; Marzban and Sangathe 2006; Roberts and Lean 2008; Ciach et al. 2007; Gourley et al. 2010). In this study, the Point-Stat Tool in METv3.0 is used to evaluate the hourly radar rainfall events of the Z-R, KF, OI and Union methods. The Point-Stat tool provides verification statistics for radar rainfall at the observation points. In this study, the radar rainfall estimation errors are assessed by using relative bias $(B)$, RootMean-Square Error (RMSE), and Pearson's correlation coefficient ( $P R \_C O R R$ ). The $B$ and RMSE are

$$
\begin{gathered}
B=\frac{\sum_{i=1}^{N}\left(f_{i}-o_{i}\right)}{\sum_{i=1}^{N} o_{i}}, \\
R M S E=\sqrt{\frac{1}{N} \sum_{i=1}^{N}\left(f_{i}-o_{i}\right)^{2}},
\end{gathered}
$$

where $N$ is the total number of radar-observation pairs, $o_{i}$ is the 1-h accumulated rainfall for the $i$ th rain gauge, and $f_{i}$ is the 1 -h accumulated radar rainfall that is matched with the $i$ th rain gauge.

To measure the strength of the linear correlation between the radar rainfall and rain gauge rainfall, we use the standard Pearson's correlation coefficient:

$$
P R_{-} C O R R=\frac{\sum_{i=1}^{N}\left(f_{i}-\bar{f}\right)\left(o_{i}-\bar{o}\right)}{\sqrt{\sum_{i=1}^{N}\left(f_{i}-\bar{f}\right)^{2}\left(o_{i}-\bar{o}\right)^{2}}} .
$$

Figure 3 displays the scatterplots of the hourly rainfall for all gauge-radar pairs of the 40 gauges that reported precipitation during the target event. Most of the CINRAD-SB rainfall estimates were lower than what the rain gauge measured for this event. The "thunderstorm" Z-R relationship that is used in the study is valid primarily for continental rain and usually underestimates tropical rain (Ulbrich and Lee 1999), which is likely associated with the typical Meiyu front in China. Tokay and Short (1996) found that small drops were dominant in convective rainfall, large drops in stratiform rainfall, and larger drops in thunder rainfall. Tropical rainfall is usually a mixture of convective rain and stratiform rain. In the $\mathrm{Z}=\mathrm{AR}^{\mathrm{b}}$ relationship, the parameter $\mathrm{A}$ increases with increasing number of drops, whereas the exponent $b$ decreases with increasing number of drops (Ulbrich 1983; Ulbrich and Atlas 2007). The $A$ in $Z=A^{b}$ relationship for tropical rain is smaller than that for thunder rain, and the $b$ for tropical rain is larger than 

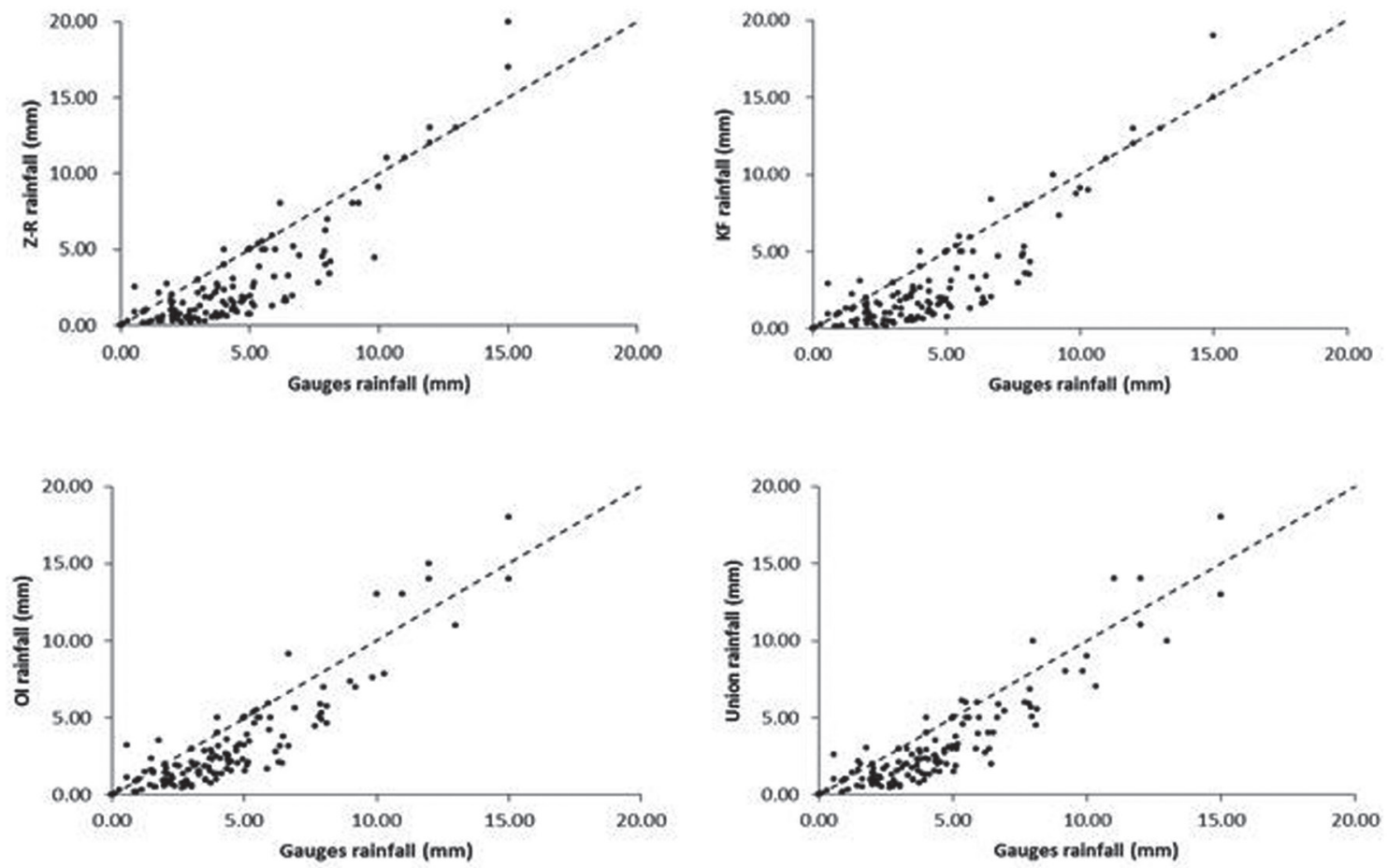

Fig. 3. Scatterplot of CINRAD (Z-R, KF, OI and Union) vs. rain gauge hourly accumulated rainfall for the event.

that for thunder rain. Thus, the estimated rain intensity when using a $\mathrm{Z}=\mathrm{AR}^{\mathrm{b}}$ relationship with larger $\mathrm{A}$ and smaller $\mathrm{b}$ will be smaller than what is estimated by using smaller $\mathrm{A}$ and larger $\mathrm{b}$ for a rain intensity $\mathrm{R}$ $>1 \mathrm{~mm} \mathrm{~h}^{-1}$ with small drops and for the same reflectivity level. This observation is why we underestimate the rainfall when using the $\mathrm{Z}=\mathrm{AR}^{\mathrm{b}}$ relationship of thunder storms to estimate tropical rainfall.

The calculated $B, R M S E$ and $P R-C O R R$ results in this case are illustrated in Figs. 4-6. The Z-R method provides the worst results because the Z-R relationship was initially developed for flat terrain (Florida) and not regions with complex topography (Woodley et al. 1975; Gagin et al. 1985). Figures 4-5 show that the $B$ values are closer to zero and the RMSE values are better with three adjustment procedures. The results expectedly show that the application of the Union method results in the best $B$ values and the lowest RMSE value, which is $<20 \mathrm{~mm}$. Compared with the Z-R estimator, the Union method that combines $\mathrm{KF}$ and $\mathrm{OI}$ reduces the magnitude of the $B$ values by $0.17-0.53$ (Fig. 4) and improves the $P R$-CORR by $0.16-0.43$ (Fig. 6). Figures $4 \mathrm{a}-\mathrm{c}$ show that the $B$ values for the Z-R, KF, OI and Union methods are closer to zero when the rainfall intensity
$>3 \mathrm{~mm} \mathrm{~h}^{-1}$ than those for the entire dataset, the Z-R, $\mathrm{KF}$, OI and Union methods provide worse $B$ values when the rainfall intensity $>5 \mathrm{~mm} \mathrm{~h}^{-1}$ than those for the entire dataset, and the KF, OI and Union methods provide better $B$ values than Z-R for the entire dataset (rainfall intensity $>0 \mathrm{~mm} \mathrm{~h}^{-1}$ ).

The OI method provides larger PR-CORR and lower RMSE than the KF method, possibly because of relatively large changes in the terrain such as mountain and hill areas and because the estimated bias is a poorer representation of the true value, resulting in high uncertainty in the estimated mean field bias for KF. However, the OI uses the radar precipitation estimation deviation at the rain gauge near the grid point to calibrate the radar estimation on the grid point and might better reflect the true distribution of the precipitation field. However, the rain gauge represents a different range because of topographically large variations. To find additional rain gauges for the calibration, expanding the search radius $\mathrm{R}$ can lead to unreasonable calibration, so the OI still has bias. Figure 1 shows that the rain gauge distribution is uneven compared to the rainfall distribution, which increases the randomness and heterogeneity of the available rain gauge distribution for calibration. If 
(a)

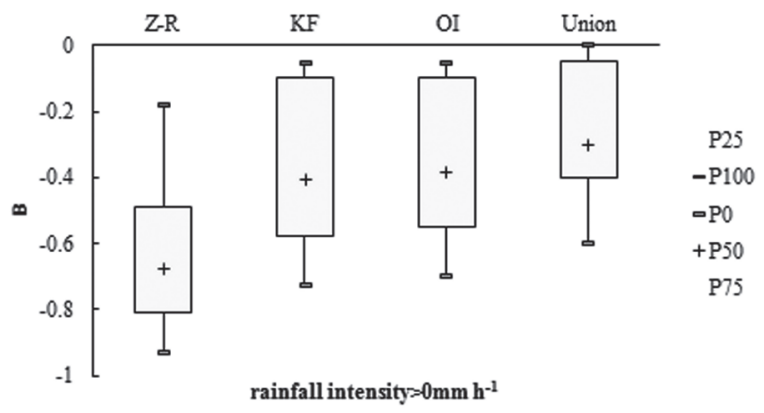

(b)

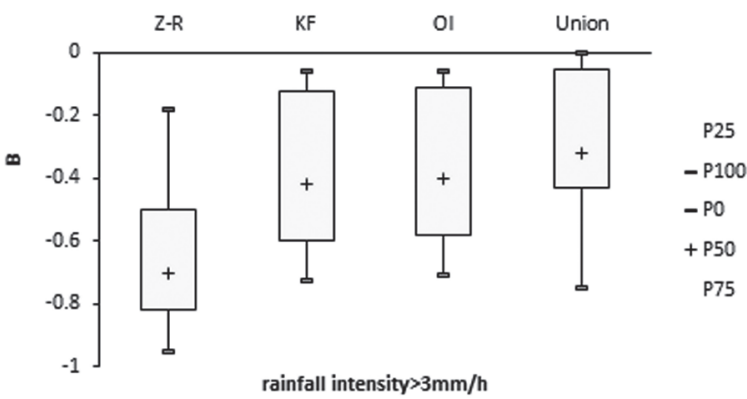

(c)

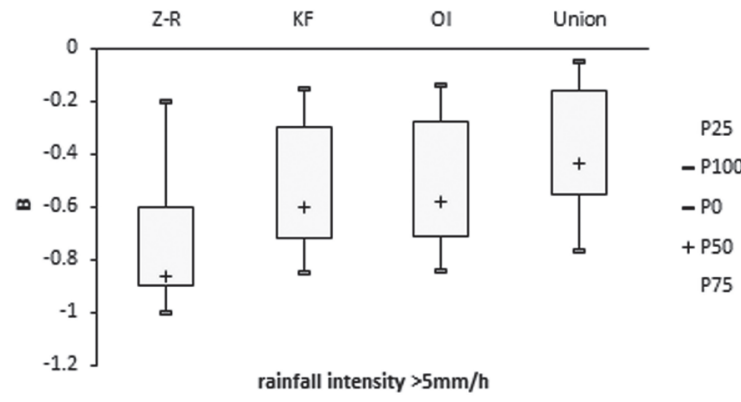

Fig. 4. Boxplots of relative bias for CINRAD with Z-R, KF, OI and Union: (a) rainfall intensity > $0 \mathrm{~mm} \mathrm{~h}^{-1}$, (b) rainfall intensity $>3 \mathrm{~mm} \mathrm{~h}^{-1}$, (c) rainfall intensity $>5 \mathrm{~mm} \mathrm{~h}^{-1}$.

only one autocorrelation coefficient is used, we cannot obtain the best calibration results. The western and southern portions of the study area are regions with mountains and hills, which will affect the measurement of low-precipitation echoes. If geo-blocked, the rain gauges receive rainfall but the radar has no echo, and OI cannot be used for calibration, which can also cause the OI results to contain bias.

The Union method provides more accurate results because the Union method uses KF to filter out the noise of the measurement process and performs a revision over the entire range of the echo. Addition-

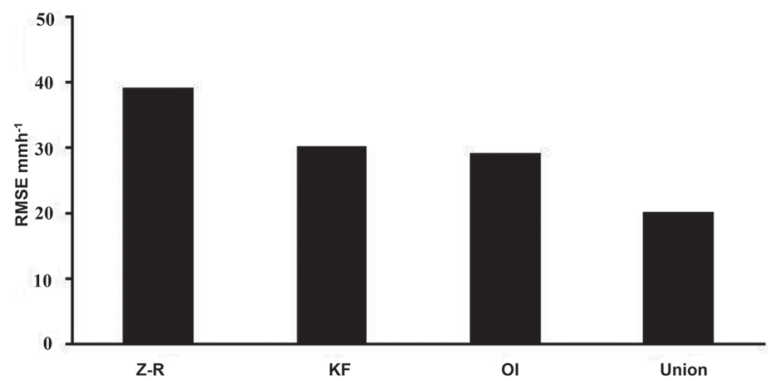

Fig. 5. Histogram of the RMSE of the CINRAD rainfall.

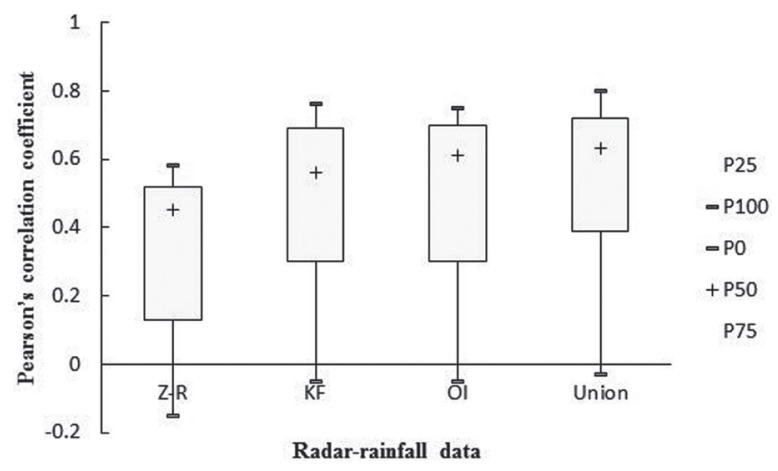

Fig. 6. Boxplot of the Pearson's correlation coefficient for the CINRAD rainfall.

ally, the Union method uses interpolation to fully consider the characteristics of the random spatial and temporal distribution of the rainfall to spatially correct the precipitation to highlight the structure of the precipitation.

\section{Radar-rainfall estimation error impacts on HEC-HMS model simulation}

\subsection{HEC-HMS model processing}

In recent decades, numerous physically based hydrological models, i.e., System Hydrology European (SHE) (Abbott et al. 1986), the Topography-based Hydrological Model (TOPMODEL) (Todini and Ciarapica 2002) and the HEC-HMS (US Army Corps of Engineers-Hydrologic Engineering Center (USACE-HEC) 2009), were developed for rainfall-runoff simulation. Open access to rainfall data that are obtained from weather radar data has driven the increasing use of physically based models. The majority of spatially distributed and physically based models that combine land use, soil or topography information compute the water balance at a highly detailed spatial and temporal resolution. 
Although this type of model is capable of the explicit spatial representation of hydrological components and accounts for the spatial variability in hydrological processes, this application is not without limitations because of its complex structure, huge number of parameters and large data requirements (Liu et al. 2002). The HEC-HMS model is physically based and is linked with Geophysical Information Systems (GIS). Considering its technical advantages, easy availability and wide use, the HEC-HMS model (version 3.4, USACE-HEC 2009) is selected to simulate flood events. The HEC-HMS contains three components: the basin model, the meteorological model, and the control specifications. The details of the model structures are given in the Technical Reference Manual and the User's Manual (USACE-HEC 2009) of the HEC-HMS.

The databases of the channel or watershed attributes that are generated by the basin-processing module of HEC-geoHMS (USACE-HEC 2010) are used as inputs to the HEC-HMS model. Because weather radar provides rainfall "observations" on a grid, the CINRAD-SB rainfall values for each sub-basin are generated by intersecting the sub-basin layer with the CINRAD-SB rainfall grids by using the conversion tools and analysis tools in Arcmap. With estimates of the rainfall in each grid cell, a time series of average rainfall depth is developed for the cell that represents each subwatershed divided by HEC-geoHMS (Fig. 7), and hourly radar rainfall data for all of the subwatersheds are used as input for the HEC-HMS model. The Thiessen Polygon method is used to calculate the areal rainfall over each subwatershed from the point rainfall values that are observed at the rain gauges. Next, the HEC-HMS v.3.4 model is applied for hydrologic modeling. The Initial and Constant model is used to compute the infiltration loss, the Soil Conservation Service (SCS) Unit Hydrograph Model (USACE-HEC 2009; Verma et al. 2010; saghafan et al. 2008) is selected to compute the runoff volumes, and the base flow is modeled by using the Exponential Recession Model (USACE-HEC 2009). The Muskingum model (USACE-HEC 2009) is used to model direct and channel flow through the calculation of necessary parameter values with some relevant GIS operations. The watershed outlet (Xixian) (marked in Fig. 1 ) is used to compare the observed flow hydrographs with the simulated flow hydrographs. The various processes are described in the Technical Reference Manual and the User's Manual of HEC-HMS (USACE-HMS 2009).
The initial parameters are selected based on literature references (Song et al. 2011; USACE-HEC 2009) and are calibrated automatically with the optimization module in the HEC-HMS model by using the trial and error method until a reasonable objective function value is obtained (USACE-HEC 2008; USACE-HEC 2009). The runoff peak error $Z$ and the sum of the runoff discharge absolute error $\mathrm{V}$ are used as the objective function (USACE-HEC 2009) values to correct the parameters. The runoff peak error $W$ represents the peak discharge error of the simulation with respect to the corresponding observations:

$$
W=\left|\frac{Q_{O}(\text { peak })-Q_{s}(\text { peak })}{Q_{O}(\text { peak })}\right| 100 \%,
$$

where $Q_{o}$ (peak) denotes the observed peak discharge $\left(\mathrm{m}^{3} \mathrm{~s}^{-1}\right)$ and $Q_{s}$ (peak) represents the simulated peak discharge from rain gauge rainfall or radar rainfall $\left(\mathrm{m}^{3} \mathrm{~s}^{-1}\right)$. The peak discharge calculation is considered in the equation without adjusting the entire volume and peak time.

The sum of the runoff volume absolute error $V$ represents the runoff volume of the simulation with respect to the corresponding observed value:

$$
V=\frac{\sum_{t=1}^{n}\left|Q_{O}(t)-Q_{S}(t)\right|}{\sum_{t=1}^{n} Q_{O}(t)} 100 \%,
$$

where $Q_{O}(t)$ and $Q_{s}(t)$ represent the $t$ time observed and simulated runoff volume, respectively. This method takes into account the adjustment of the peak discharge, the overall runoff volume, and the peak time for the simulated flow process. The values of $W$ and $V$ are controlled to less than $15 \%$ (Wong et al. 2006), and the flood peak time error is controlled for less than $3 \mathrm{~h}$. Iterative calculations (USACE-HEC 2009) are used to calibrate the model.

With a computational time step of $1 \mathrm{~h}$, the model of the Xixian watershed is calibrated by using the 1-h rainfall, discharge and evaporation data from May to September in 2006 and 2007. The Nash-Sutcliffe model efficiency coefficient is used to assess the predictive power of hydrological models, defined as

$$
E=1-\frac{\sum_{t=1}^{T}\left(D_{o}(t)-D_{s}(t)\right)^{2}}{\sum_{t=1}^{T}\left(D_{o}(t)-\overline{D_{0}}\right)^{2}},
$$




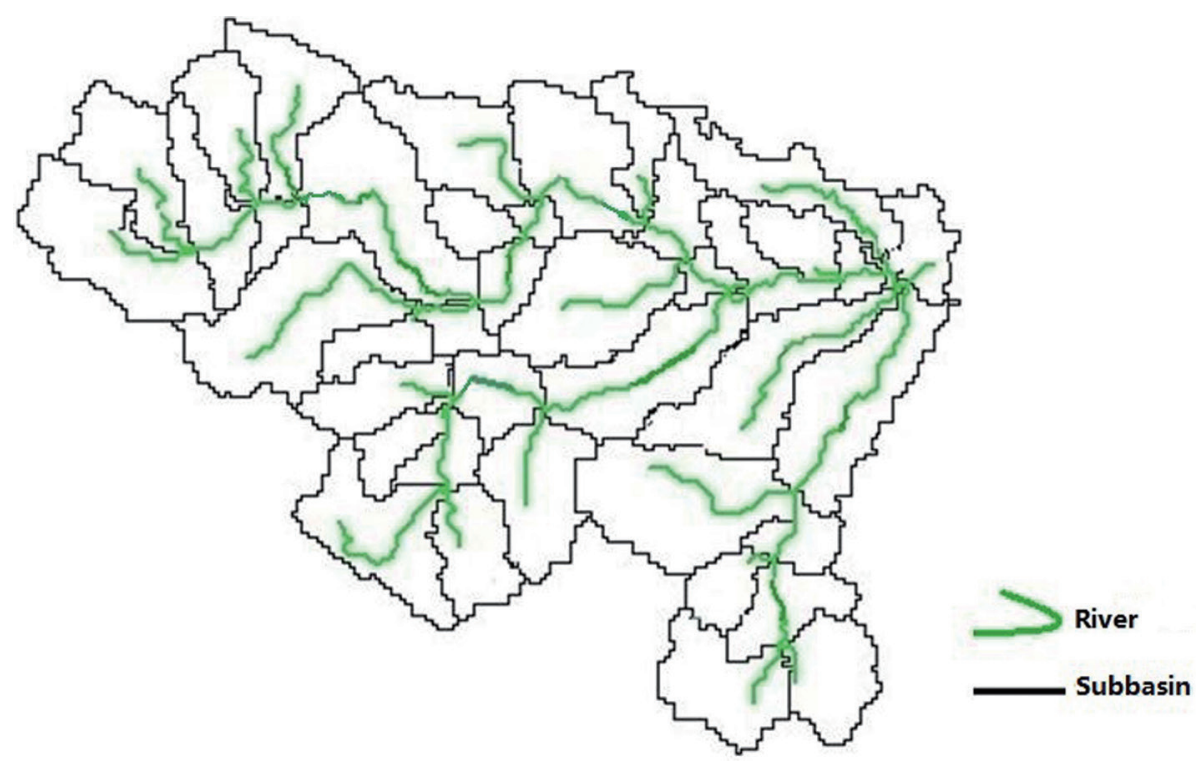

Fig. 7. Stream and sub-basin map of the basin around the Huaihe Xixian hydrological station.

Table 1. Calibrated parameters and ranges of the HEC-HMS values

\begin{tabular}{ccc}
\hline Parameter & Initial setting for the parameter & Range of the value \\
\hline Initial Loss $(\mathrm{mm})$ & 0.2 & $0-50$ \\
Constant Loss Rate $\left(\mathrm{mm} \mathrm{h}^{-1}\right)$ & 1.2 & $0-20$ \\
SCS Lag $(\mathrm{h})$ & 12 & $0.1-24$ \\
Initial Baseflow Rate $\left(\mathrm{m}^{3} \mathrm{~s}^{-1}\right)$ & 20 & $0-50$ \\
Recession Constant & 0.95 & $0.9-0.99$ \\
Recession Threshold Ratio & 0.1 & $0-1$ \\
\hline
\end{tabular}

where $\overline{D_{0}}$ is the mean of the observed discharges, $D_{S}(t)$ is the modeled discharge and $D_{o}(t)$ is the observed discharge at time $t$ (Nash and Sutcliffe 1970). Nash-Sutcliffe efficiencies can range from $-\infty$ to 1 . An efficiency of $1(E=1)$ corresponds to a perfect match between the modeled discharge and the observed data. An efficiency of $0(E=0)$ indicates that the model predictions are as accurate as the mean of the observed data, whereas an efficiency that is less than zero $(E<0)$ occurs when the observed mean is a better predictor than the model or, in other words, when the residual variance (described by the numerator in the expression above) is larger than the data variance (described by the denominator). Essentially, the closer the model efficiency is to 1 , the more accurate the model is.

The Nash-Sutcliffe model efficiency coefficient exceeds 0.75 , the peak discharge error is within $10 \%$, and the error of the peak time is within $3 \mathrm{~h}$. The calibrated parameters and ranges of the HEC-HMS values are presented in Table 1.

\subsection{Hydrologic evaluation}

The calibrated HEC-HMS model is used to simulate runoff during the rainfall-runoff storm by using radar rainfall with a computational time interval of $1 \mathrm{~h}$. To evaluate the rainfall estimation impacts on the runoff process, the model simulations are driven with inputs of the CINRAD-SB rainfall based on the $\mathrm{Z}-\mathrm{R}$ and precipitation bias correction with the KF, OI and Union methods. Fig. 8 shows the simulated and observed discharges at the watershed outlet for the target event when using inputs from the CINRADSB-based rainfall estimation and rain gauge rainfall. These radar-based hydrographs show overall patterns that are relatively similar to the hydrograph of the observed streamflow; however, different degrees of 


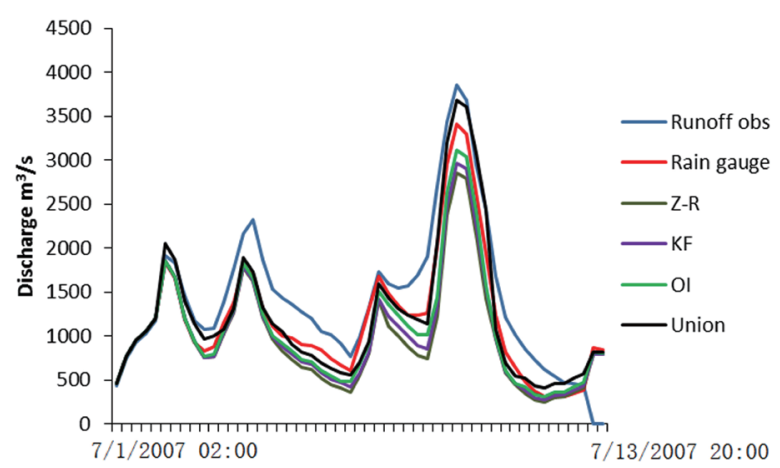

Fig. 8. Plotted hydrographs of the simulated runoff for the event with a computational time step of $1 \mathrm{~h}$ at the Xixian outlet. Obs represents the observed runoff discharge, and Obs-simulation denotes the simulated runoff when using rain gauge rainfall.

agreement are observed between the modeled and observed discharges. The error in the peak time of the hydrographs is within $3 \mathrm{~h}$.

The simulation skill is improved after the rainfall biases (Fig. 4) are removed, which agrees with the study by Habib et al. (2008). Several possible explanations exist for this result. The translation of the error from precipitation to streamflow is strongly affected by surface characteristics as topography, land use, and soils (Knebl and Yang 2008). The model is run at the subwatershed scale, and the subwatersheds in the study area are relatively large (e.g., the smallest subwatershed area is $263 \mathrm{~km}^{2}$ ). In a large subwatershed, the averaging of watershed parameters could lead to model error. The availability of rain gauge data limits the calibration of the background field for the $\mathrm{KF}$ and OI methods. A smaller improvement is noted for KF and OI relative to the Union method over the Z-R. Radar data at a $1 \times 1-\mathrm{km}$ resolution and the point gauge rainfall are converted for each subwatershed. The use of data values that are derived at different resolutions to determine runoff may lead to errors in the outflow hydrographs. The streamflow response for the event appears to be more heavily influenced by rainfall forcing than the combination of model error and parametric uncertainty.

Skill scores are calculated to further assess the impact of radar error on hydrologic simulation. The skill scores of the peak discharge $S_{P K}$ and runoff volume $S_{R V}$ are computed by using the following equations:

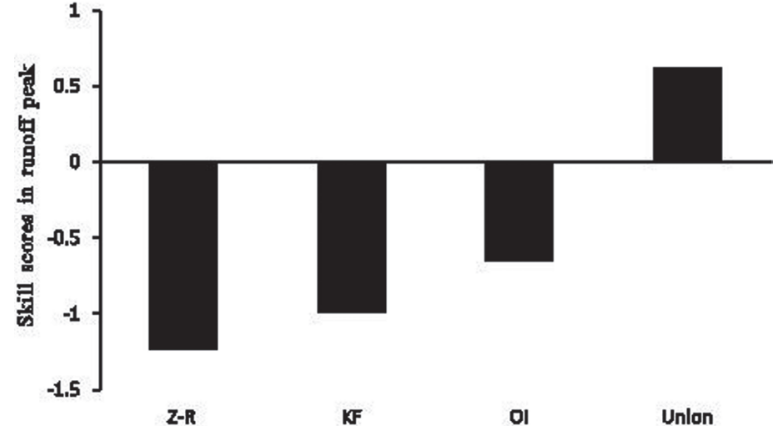

Fig. 9. Skill scores of the peak discharge.

$$
\begin{aligned}
& S_{P K}=\frac{P K-P K^{r e f}}{P K^{\text {perf }}-P K^{r e f}}, \\
& S_{R V}=\frac{R V^{\text {erf }}-R V^{r e f}}{R V^{\text {ref }}},
\end{aligned}
$$

where $P K(R V), P K^{r e f}\left(R V^{r e f}\right)$ and $P K^{r e f}\left(R V^{\text {perf }}\right)$ are the radar-driven simulated peak discharge (runoff volume), the reference peak discharge (runoff volume) that is estimated by using rain gauge rainfall, and the observed peak discharge (runoff volume), respectively. The skill score $S_{P K}$ is interpreted as a percentage improvement over the reference peak discharge (Wilks 2005). The use of skill scores $S_{P K}$ is often motivated by a desire to equalize the effects of modeling and parameter estimation uncertainties (Wilks 2005). If $P K=P K^{\text {perf }}$, the skill score attains its perfect value of 1 . If $P K=P K^{r e f}$, then $S_{P K}=0$, indicating no improvement over the reference peak discharge that is obtained by using the rain gauge rainfall in the model calibration. If the values that are under evaluation are inferior to the reference values with respect to the accuracy measure $P K$, then $S_{P K}<$ 0 . The range of the $S_{R V}$ value has a similar meaning to that of the $S_{P K}$ value.

The skill scores $S_{P K}$ and $S_{R V}$ for the target event are shown in Figs. 9 and 10. Z-R, KF and OI produce worse hydrologic skill than the simulation that is forced by the rain gauge rainfall input. Inputs from the Union method yielded a runoff simulation that is more skillful than that of the rain gauge rainfall input. The values of $S_{P K}$ and $S_{R V}$ for the Union method are 0.6 and 0.12 , respectively. The Union method, when combined with KF and OI, has the highest hydrologic skill, and the radar rainfall estimation error analysis indicates that the Union method produces the best $B$ value. The hydrologic simulations according to the $S_{P K}$ and $S_{R V}$ scores are rather sensitive to rainfall bias 


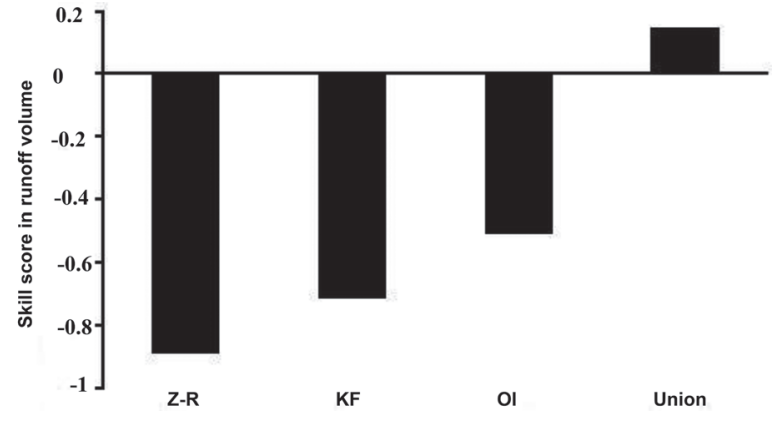

Fig. 10. Skill scores of the runoff volume.

with respect to the magnitude of the $B$ values that are found in the radar rainfall evaluation compared with $S_{P K}$ and $S_{R V}$. These findings confirm that rainfall forcing dominates stream simulation for events in the large watershed (Yao et al. 2015).

\section{Summary and conclusions}

The Xixian watershed, which is located at the upper end of the HB, where flood disasters frequently occur, was used to 1) evaluate radar rainfall estimation from the CINRAD-SB with KF, OI and Union bias correction methods and 2) assess the impact of radar rainfall estimation on hydrologic simulations by using the HEC-HMS model. Hourly precipitation from Z-R, $\mathrm{KF}$, OI and Union were compared with rain gauge accumulations during a flood event from July 1 to 13 in 2007. The main findings from the rain gauge evaluation are summarized as follows:

- The $B$ values and RMSE values for radar rainfall with three bias correction procedures are better than those of the Z-R radar data. The $B$ values of the Union method, which is composed of KF and OI methods, are the closest to zero compared to the other radar data. The Union method also has the smallest RMSE.

- The $B$ values for the Z-R, KF, OI and Union methods are closer to zero when the rainfall intensity is $>3 \mathrm{~mm} \mathrm{~h}^{-1}$ than those for the entire dataset, and the $B$ values for KF, OI and Union are better than Z-R for the entire dataset.

The impacts of the CINRAD-SB rainfall estimation on hydrologic simulation were evaluated. The rain gauge data were input into the HEC-HMS to optimize the parameters. Radar rainfall estimation was used to force the calibrated model.

- Despite the differences in the input data, the shape of the overall model hydrograph is not different for both the gauged and CINRAD-SB input (Figs.
3-6), but the total runoff depths (or volume) are different, as shown in Fig. 8.

- The runoff simulation that was forced by the Union method is the best and shows improvement over the peak discharge that was obtained by using the rain gauge rainfall in the model calibration.

- The simulations that were forced by the CINRAD-SB rainfall estimation with $\mathrm{KF}$, OI and Union bias correction outperform the Z-R relationship. Better simulation occurred with the Union method. The results highlight the importance of combining $\mathrm{KF}$ and $\mathrm{OI}$, which are used to revise deviations from different causes, to improve the accuracy of the estimated regional precipitation.

The conclusions were based on a case study. Additional investigations are required to generalize the conclusions in this study. Future studies will focus on CINRAD-SB rainfall estimation errors in the HB for all events that range from common to rare. Because of the current business situation at the Zhumadian radar station, all mixed precipitation estimates use the same $\mathrm{Z}$ (reflectivity)-R (precipitation intensity), namely, $\mathrm{Z}=$ $300 \mathrm{R}^{1.4}$. Although the Union method was used in this study to calibrate the radar rainfall estimation and the radar rainfall was improved, the results still contain bias. The "thunderstorm" Z-R relationship that was used in the study is valid primarily for continental rain and usually underestimates tropical rain, which is likely associated with the typical Meiyu front in China. In future studies, we plan to test the "tropical" $\mathrm{Z}-\mathrm{R}$ relationship such that $\mathrm{Z}=250 \mathrm{R}^{1.2}$, which alone might substantially reduce the rainfall estimation error.

\section{Acknowledgments}

This work was jointly sponsored by the 973 Program (2013CB430102), the National Natural Science Foundation of China (41105077, 41205082, and 41205086), the Jiangsu Provincial Natural Science Foundation of China (BK2012859), the Open Project Program of Key Laboratory of Meteorological Disaster of Ministry of Education, NUIST (KLME 1311) and the Priority Academic Program Development of Jiangsu Higher Education Institutions (PAPD). The authors gratefully acknowledge Dr. David Gochis at the National Center for Atmospheric Research for his assistance with this study. The authors gratefully acknowledge anonymous two reviewers.

\section{References}

Abbott, M. B., J. C. Bathurst, J. A. Cunge, P. E. O'Con- 
nell, and J. Rasmussen, 1986: An introduction to the European Hydrological System-System Hydrologique Europeen, "SHE". 2: Structure of a physically-based, distributed modelling system. J. Hydrol., 87, 61-77.

Austin, P. M., 1987: Relation between measured radar reflectivity and surface rainfall. Mon. Wea. Rev., 115, 1053-1070.

Baldwin, M. E., and J. S. Kain, 2006: Sensitivity of several performance measures to displacement error, bias, and event frequency. Wea. Forecasting, 21, 167-181.

Baldwin, M. E., J. S. Kain, and M. P. Kay, 2002: Properties of the convection scheme in NCEP's Eta Model that affect forecast sounding interpretation. Wea. Forecasting, 17, 1063-1079.

Cai, T., Q. Li, M. Yu, G. Lu, L. Cheng, and X. Wei, 2012: Investigation into the impacts of land-use change on sediment yield Characteristics in the upper Huaihe River basin, China. Phys. Chem. Earth, 53, 1-9.

Casati, B., and L. J. Wilson, 2007: A new spatial-Scale decomposition of the brier score: Application to the verification of lightning probability forecasts. Mon. Wea. Rev., 135, 3052-3069.

Chen, Z., W. C. Zhang, and C. A. Yan, 2014: Application of ESSI distributed hydrological model in Huaihe River Basin. J. China Hydro., 34, 17-25.

Chu, Z. G., Y. Yin, and S. S. Gu, 2013: Characteristics of velocity ambiguity for CINRAD-SA doppler weather radar. J. Atmos. Sci., 50, 221-227.

Chumchean, S., A. Seed, and A. Sharma, 2004: Application of scaling in radar reflectivity for correcting rangedependent bias in climatological radar rainfall estimates. J. Atmos. Oceanic Technol., 21, 15451556.

Ciach, G. J., W. F. Krajewski, and G. Villarini, 2007: Product-error-driven uncertainty model for probabilistic quantitative precipitation estimation with NEXRAD data. J. Appl. Meteor., 8, 1325-1347.

Davis, C., B. Brown, and R. Bullock, 2006: Object-based verification of precipitation forecasts. Part I: Methodology and application to mesoscale rain areas. Mon. Wea. Rev., 134, 1772-1784.

Developmental Tested Center, 2010: Model evaluation tools version 3.0 (METv3.0). [Available at http://www. dtcenter.org/met/users.]

Dinku, T., E. N. Anagnostou, and M. Borga, 2002: Improving radar-based estimation of rainfall over complex terrain. J. Appl. Meteor., 41, 1163-1178.

Eloise, M. B., and P. M. Atkinson, 2011: A comparison of gauge and radar precipitation data for simulating an extreme hydrological event in the Severn Uplands, UK. Hydrol. processes, 25, 795-810.

Gagin, A., D. Rosenfeld, and D. E. Lopez, 1985: The relationship between height and precipitation characteristics of summertime convective cells in Florida. $J$. Atmos. Sci., 42, 84-94.

Gourley, J. J., S. E. Giangrande, Y. Hong, Z. L. Flamig, T.
Schuur, and J. A. Vrugt, 2010: Impacts of polarimetric radar observations on hydrologic simulation. J. Appl. Meteor., 11, 781-796.

Habib, E., A. V. Aducala, and E. A. Meselhe, 2008: Analysis of radar-rainfall error characteristics and implications for streamflow simulation uncertainty. Hydro. Sci. J., 53, 568-587.

Huang, Y., W. Hu, Y. J. He, and J. Y. Ye, 2010: Multi-radar rainfall estimation in Huaihe basin. J. Meteor. Sci., 30, 268-273.

Jiao, M. Y., R. H. Jin, and D. Chen, 2008: Meteorological and hydrological characteristics of flood related torrential rain over Huaihe River Basin in 2007. J. Appl. Meteor. Sci., 19, 257-265.

Joss, J., and R. Lee, 1995: The application of radar-gauge comparisons to operational precipitation profile corrections. J. Appl. Meteor, 34, 2612-2630.

Kitchen, M., and P. M. Jackson, 1993: Weather radar performance at long range-simulated and observed. $J$. Appl. Meteor., 32, 975-985.

Knebl, M. R., and Z. L. Yang, 2008: Assessing the capability of a regional-scale weather model to simulate extreme precipitation patterns and flooding in central Texas. Wea. Forecasting, 23, 1102-1126.

Li, J. T., and P. C. Zhang, 1996: Optimum interpolation method used for measuring regional precipitation with weather radar. J. Oceanog. Taiwan Strait, 15, 255-260.

Li, Z. J., J. T. Liu, W. Z. Ge, and K. Zhao, 2004: Coupling of weather radar data with hydrological model and its application to flood forecasting. J. Hehai Univ. (Nat. Sci.), 6, 601-606.

Liu, J. T., and Z. J. Li, 2004: Weather radar rainfall databased flood forecasting model. J. Hehai Univ. (Nat. Sci.), 5, 1-4.

Liu, X. Y., J. T. Mao, J. R. Li, and Y. J. Zhu, 2002: Radar rainfall estimation and its application on runoff simulation over Shiguanhe catchments. Acta Scientiarum Naturalum Univ. Pekinensis, 38, 342-349.

Marzban, C., and S. Sandgathe, 2006: Cluster analysis for verification of precipitation fields. Wea. Forecasting, 21, 824-838.

Mikhail, A. A., and R. C. Elvander, 1972: Optimum interpolation from observations of mixed quality. Mon. Wea. Rev., 100, 611-623.

Moon, J., R. Srinivasan, and J. H. Jacobs, 2004: Streamflow estimation using spatially distributed rainfall in the Trinity River basin, Texas. Trans. ASAE, 47, 14451451.

Nash., J. E., and J. V. Sutcliffe, 1970: River flow forecasting through conceptual models part I - A discussion of principles. J. Hydrol., 10, 282-290.

Nehrkorn, T., and R. N. Hoffman, 1996: Development of a mallscale, relocatable optimum interpolation data analysis system. Proceeding of 11th Conf. on Numerical Weather Prediction, Amer. Meteor. Soc., Norfolk, 
VA, 19-23.

Niu, Y., X. D. Liu, and Q. Wang, 2014: Measurement and arithmetic of river runoff based on radar monitoring. Mountain Res., 32, 685-690.

Roberts, N. M., and H. W. Lean, 2008: Scale-selective verification of rainfall accumulations from high-resolution forecasts of convective events. Mon. Wea. Rev., 136, 78-97.

Saghafian, B., H. Farazjoo, B. Bozorgy, and F. Yazdandoost, 2008: Flood intensification due to changes in land use. Water Resour. Manage., 22, 1051-1067.

Sharif, H. O., F. L. Ogden, W. F. Krajewski, and M. Xue, 2004: Statistical analysis of radar rainfall error propagation. J. Appl. Meteor. 5, 199-212.

Shi, P., X. X. Ma, and Y. B. Hou, 2003: Effects of land-use and climate change on hydrological processes in the upstream of Huai River, China. Water Resour. Manage, 27, 1263-1278.

Song, X. M., F. Z. Kong, and Z. X. Zhu, 2011: Application of Muskingum routing method with variable parameters in ungauged basin. Water Sci. Eng., 4, 1-12.

$\mathrm{Su}$, F., Y. Hong, and D. P. Lettenmaier, 2008: Evaluation of TRMM Multisatellite Precipitation Analysis (TMPA) and its utility in hydrologic prediction in the La Plata basin. J. Appl. Meteor., 9, 622-640.

Todini, E., and L. Ciarapica, 2002: The Topkapi model. Mathematical Models of Large Watershed Hydrology. Water Resources Publication, 914 pp.

Tokay, A., and D. A. Short, 1996: Evidence from tropical raindrop spectra of the origin of rain from stratiform versus convective clouds. J. Appl. Meteor., 35, $355-371$.

Ulbrich, C. W., 1983: Natural variations in the analytical form of the raindrop size distribution. J. Climate Appl. Meteor., 22, 1764-1775.

Ulbrich, C. W., and L. G. Lee, 1999: Rainfall measurement error by WSR-88D radars due to variations in Z-R law parameters and the radar constant. J. Atmos. Oceanic Technol., 16, 1017-1024.

Ulbrich, C. W., and D. Atlas, 2007: Microphysics of raindrop size spectra: Tropical continental and maritime storms. J. Appl. Meteor. Climatol., 46, 1777-1791.

US Army Corps of Engineers Hydrologic Engineering Center, 2008: Hydrologic modeling system HEC-HMS. User's manual version 3.4. [Available at http://www.hec.usace.army.mil.]

US Army Corps of Engineers Hydrologic Engineering Center, 2009: Hydrologic modeling system HEC-HMS. User's manual version 3.4. [Available at http://www. hec.usace.army.mil.]

US Army Corps of Engineers Hydrologic Engineering Center, 2010: HEC-GeoHMS, geospatial hydrologic modeling extension. User's manual version 5.0. [Available at http://www.hec.usace.army.mil.]

Verma, A. K., M. K. Jha, and R. K. Mahana, 2010: Evaluation of HEC-HMS and WEPP for simulating watershed runoff using remote sensing and geographical information system. Paddy. Water Environ., 8, 131-144.

Wilks, D. S., 2005: Statistical Methods in the Atmospheric Sciences. Academic Press, 704 pp.

Wilson, J. W., and E. A. Brandes, 1979: Radar measurement of rainfall-a summary. Bull. Amer. Meteor. Soc., 60, 1048-1058.

Wong, S. W., B. S. Tang, and B. V. Horen, 2006: Strategic urban management in China: A case study of Guangzhou development district. Habitat Int., 30, 645-667.

Woodley, W. L., A. R. Olsen, A. Herndon, and V. Wiggert, 1975: Comparison of gage and radar methods of convective rain measurements. J. Appl. Meteor, 14, 909-928.

Xu, J. J., D. W. Yang, and Z. G. Cai, 2007: Distributed hydrological model combining with radar rainfall data for regional flood forecast of three corges. J. Yangtze River Sci. Res. Inst., 24, 42-49.

Yang, C. G., Z. B. Yu, Z. H. Lin, Z. C. Hao, Z. L. Wang, and M. Li , 2009: Study on watershed hydrologic processes using TRMM satellite precipitation radar products. Adv. Water Sci. 20, 461-467.

Yao, Y. F., T. J. Cai, C. Y. Ju, and C. X. He, 2015: Effect of reforestation on annual water yield in a large watershed in northeast China. J. For. Res., 26, 697-702.

Yin, Z. H., and P. Y. Zhang, 2005: Radar rainfall calibration by using the Kalman Filter method. J. Appl. Meteor. Sci., 16, 213-219.

Zhao, L. N., X. D. Yang, D. Qi, and R. H. Liu, 2007: The analysis of precipitation and flooding features in the Huaihe River Basin during the summer of 2007. Climatic. Environ. Res., 12, 728-738. 